\title{
Escritura áurea, ficción y géneros narrativos: problemas historiográficos
}

\author{
José Julio Martín Romero \\ Universidad de Jaén
}

\begin{abstract}
Título: Escritura áurea, ficción y géneros narrativos: problemas historiográficos.

Title: Golden Age Writing, Fiction and Narrative Genres: Historiographical Problems.

Resumen: Este artículo analiza ciertos problemas relativos a la clasificación tradicional de los géneros narrativos del Siglo de Oro en la historia literaria. Dicha clasificación presenta algunas incongruencias e impide ver con claridad tanto la evolución de las formas narrativas en los siglos XVI y XVII como los vínculos existentes entre obras consideradas de géneros distintos. En este sentido, los testimonios coetáneos demuestran, por una parte, que existía de alguna manera una recepción común de las obras de ficción y, por otra, que los límites entre esos géneros no resultaban tan claros como se piensa. Asimismo, el artículo analiza el papel de la imitatio en la aparición de los géneros y en la permeabilidad entre ellos.

Palabras clave: Ficción del Siglo de Oro, Imitatio, Géneros narrativos áureos, Historia literaria.

Abstract: This article analyses some problems related to the traditional classification of narrative genres of the Golden Age as commonly used by Literary History. This classification presents inconsistencies and hinders a good understanding of both the evolution of narrative forms in the $X V I^{\text {th }}$ and XVII ${ }^{\text {th }}$ centuries and the links between works which are thought to belong to different genres. In this way, coetaneous testimonies reveal that fictional works were perceived as a general group and they also show that the boundaries between these genres were not as fixed as believed. Besides, this article also studies the role of imitation on the emergence of literary genres, and on the permeability between them.

Key words: Golden Age fiction, Imitatio, Narrative Genres of the Golden Age, Literary History.

Fecha de recepción: 9/6/2020.

Date of Receipt: 9/6/2020.

Fecha de aceptación: 27/7/2020.

Date of Approval: 27/7/2020.
\end{abstract}

Es sabido que en el Quijote encontramos una reivindicación de la ficción apoyándose en la no necesidad de realismo — ni de realidad_ — en el arte; especialmente significativo al respecto es el momento en que el loco hidalgo explica a Sancho la idealización de las damas en la literatura: 
¿Piensas tú que las Amariles, las Filis, las Silvias, las Dianas, las Galateas, las Fílidas y otras tales de que los libros, los romances, las tiendas de los barberos, los teatros de las comedias, están llenos, fueron verdaderamente damas de carne y hueso, y de aquéllos que las celebran y celebraron? No, por cierto, sino que las más se las fingen, por dar subjeto a sus versos y porque los tengan por enamorados y por hombres que tienen valor para serlo ${ }^{1}$.

Se trata de una justificación de la ficción per se. No es el primer testimonio de ello; ya a finales del siglo XV, Garci Rodríguez de Montalvo ofreció una interesante reflexión sobre los diversos grados de ficción en el prólogo a su versión de Amadis de Gaula, con el objetivo de justificar su labor, claramente vinculada con la historia ficta ${ }^{2}$. Aunque es cierto que habla de que se trata de autores de "más baxa suerte", el hecho de que su propia escritura se encuadre en este ámbito no deja de ser una justificación en sí del carácter ficticio:
Otros uvo de más baxa suerte que escribieron, que no solamente edificaron sus obras sobre algún cimiento de verdad, mas ni sobre el rastro della. Estos son los que compusieron las historias fengidas en que se hallan las cosas admirables fuera de la orden de natura, que más por nombre de patrańas que de crónicas con mucha razón deven ser tenidas y llamadas ${ }^{3}$.

Estas defensas eran necesarias en esos años en los que menudeaban las críticas contra la literatura de ficción, críticas apoyadas en motivos sobre todo morales, pues los libros se concebían únicamente como forma de transmitir una verdad, fuera historiográfica, fuera moral ${ }^{4}$. De hecho, el

1 Miguel de Cervantes Saavedra, El ingenioso hidalgo Don Quijote de la Mancha, eds. Florencio Sevilla y Antonio Rey Hazas, Alcalá de Henares, Centro de Estudios Cervantinos, 1994, p. 251.

2 Sobre el carácter de crónica ficcional de Amadis, vid. James Donald Fogelquist, El Amadis y el género de la historia fingida, Madrid, J. Porrúa, 1982.

3 Garci Rodríguez de Montalvo, Amadís de Gaula, ed. Juan Manuel Cacho Blecua, Madrid, Cátedra, 1991, I, p. 223.

4 Sobre la conflictiva relación entre verdad y ficción, vid. Consolación Baranda, "El apólogo y el estatuto de la ficción en el Renacimiento", Studia Aurea, 1 (2007), pp. 1-33. 
mismo Garci Rodríguez de Montalvo justificaba el provecho que se podía extraer de la ficción alegando su carácter ejemplar:

Por cierto, a mi ver, otra cosa no salvo los buenos enxemplos y doctrinas que más a la salvación nuestra se allegaren, porque seyendo permitido de ser imprimida en nuestros coraçones la gracia del muy alto Señor para a ellas nos llegar, tomemos por alas con que nuestras ánimas suban a la alteza de la gloria para donde fueron criadas 5 .

De hecho, el rechazo de la ficción forzó a los autores a justificar su escritura mediante la inclusión de valores morales, de sentencias, de elementos de carácter ejemplarizante o de cualquier forma que permitiera concebir su texto como una obra de la que se extrajera un provecho moral ${ }^{6}$.

No obstante, poco a poco se fue reivindicando el valor de la ficción en sí misma; no fue infrecuente que se mencionara la necesidad de la "recreación" . Así, Ortúñez de Calahorra en el prólogo a Espejo de príncipes y caballeros (1555) afirmaba: "ay otra especie de libros, de poesía y de historias compuestas, los quales, ya que no sean para tanto provecho, son para alguna manera de placer y recreación del hombre"8. Pero incluso así se incide en el valor moral de ese descanso: "Que leyéndolos en algunas horas de ociossidad, sirven y aprovechan a la ánima en la apartar de la ociosidad, la qual es gran materia para el vicio, y muy aparejada para la infamia"9. Por tanto, se justifica esa recreación solo por el valor moral que supone: Ortúñez de Calahorra defiende que el hecho de dedicar tiempo al entretenimiento, a la ficción, aparta al hombre de otras actividades más

5 Garci Rodríguez de Montalvo, op. cit., p. 223.

6 En el ámbito de la literatura caballeresca, uno de los más castigados por parte de los moralistas, la inclusión de aspectos sapienciales no se limitaba a ser tópico de justificación, sino que realmente incorporaban elementos sapienciales en sus textos (José Julio Martín Romero, “Buenas dotrinas y enxemplos'. Aspectos sapienciales y didácticos en los libros de caballerías”, Memorabilia. Boletín de Literatura Sapiencial, 8 (2004-2005), pp. 1-8).

7 Sobre el concepto de "eutrapelia" y la literatura de ficción como recreación honesta, vid. Barry Taylor, "El honesto placer de la lectura: presencia de la eutrapelia en los prólogos de los libros de caballerías", Historias Fingidas, 5 (2017), pp. 131-143.

8 Diego Ortúnez de Calahorra, Espejo de príncipes y cavalleros [El cavallero del Febo], ed. Daniel Eisenberg, Madrid, Clásicos Castellanos, Espasa-Calpe, 1975, I, p. 12.

9 Ibidem. 
peligrosas para su alma. En cualquier caso, se trata de una visión positiva de la ficción, que ya no aparece considerada como mal — ni tan siquiera como mal menor-, sino como una herramienta útil para el hombre ${ }^{10}$.

Más interesante resulta el testimonio de un libro anterior, el Baldo, impreso en 1542. Este original texto utiliza como fuente no solo el poema homónimo en latín macarrónico debido a Teófilo Folengo, sino otras muchas obras. Pues bien, en el "prólogo sobre la poesía de Merlino Cocayo" que encabeza el libro, no se admite que la ficción pueda ser considerada "mentirosa" (como le achacaban los moralistas):

vengo a las fábulas, las cuales claro está que muy poco daño traen porque ya se nombran por cosas falsas y la cosa clara no engańa. Ellas son, según aquello que se preguntava a Aulo Gelio, que si cuando alguno mentía y primero avisava como avía de mentir, si me[n] tía o decía verdad ${ }^{11}$.

Defiende, por tanto, que no se puede considerar mentira lo que se avisa previamente que no es cierto, lo cual se antoja una de las justificaciones del concepto de ficción más interesantes de la época; así, en este pasaje del Baldo se explicita el pacto con el lector, que acepta la no veracidad de lo que lee y, por tanto, no se ve engañado. Curiosamente es una opinión contraria a la de Alejo Venegas, que criticaba las obras de ficción, ya que la letra impresa gozaba de una autoridad (y, por tanto, se consideraban vehículo de verdad) que se contraponía al carácter ficticio de esos textos ("qualquier libro impresso tiene auctoridad para que le crean lo que dixere" $)^{12}$. El Baldo castellano salió a la luz en 1542, mientras que la obra de Venegas, redactada en 1539, se publicaría en 1540 . Se trata, por tanto, de fechas muy próximas, lo que revela que en esos años se estaba produciendo una reflexión y un debate sobre este tema. En

10 De todas formas, Ortúñez de Calahorra también defiende su texto recordando su valor ejemplarizante y las lecciones filosóficas que de él se extraen.

11 Baldo, ed. Folke Gernert, Alcalá de Henares, Centro de Estudios Cervantinos, 2002, p. 5.

12 Alejo Venegas, Primera parte de las diferencias de libros q[ue] ay en el universo, pról. de Daniel Eisenberg, Barcelona, Puvill Libros, 1983. Tomo la cita de Donatella Gagliardi, "Malos libros en la Espańa del XVI: la fábula milesia de Vives a Venegas", Studia Aurea, 3 (2008), pp. 1-16 (p. 6). 
dicho debate el rechazo de la ficción era sin duda la opinión más extendida, de ahí el aluvión de críticas a este tipo de literatura, considerada como una pérdida de tiempo (ya desde la época del canciller Pero Lope de Ayala, recordemos), cuando no abiertamente dañina y moralmente perjudicial.

No obstante, tampoco hay que olvidar que algunas críticas no se dirigían contra su carácter ficticio, sino contra la ausencia de verosimilitud. La necesidad de ese carácter verosímil es mencionada por Alejo Venegas, quien en su Agonía del tránsito de la muerte (1553) hablaba de la "poética narración" de esta forma: "La poética narración es vna explicación por rodeos de fingimientos, con tal que no salgan de los límites de la razón: porque no es otra cosa, sino una fiction racional: que por vía de admiración guía al entendimiento del oydor"13.

En este pasaje, Venegas parece aceptar la honestidad de la ficción, siempre y cuando no narre asuntos inverosímiles ("no salgan de los límites de la razón"), pero lo cierto es que se refiere aquí únicamente a aquellas narraciones fingidas destinadas a la explicación de un determinado concepto o idea, ya que está hablando de diversas formas de "declaración". En tanto que en la época la ficción había de vincularse con algún tipo de provecho moral, sus palabras parecen definir la visión ortodoxa de lo que ha de ser una historia fingida: una ficción con valor moral. Esta idea coincide con la expresada más arriba, el rechazo de aquella ficción que no contuviera en sí alguna verdad, histórica o moral, de la que el lector pudiera aprovecharse.

Este contexto explica la abundancia de críticas en la época a la lectura de los libros de caballerías, críticas de tipo moral, no literario ${ }^{14}$. Estos ataques, por otra parte, rara vez se dedicaban exclusivamente a este género. De hecho, lo más frecuente es que incluyeran todo tipo de obras de ficción tanto en prosa como en verso; de esta manera, los Amadises compartían reproches con las Dianas, los Orlandos e incluso Garcilaso y Boscán, sin olvidar La Celestina. Además de la tan traída cita de Pedro

13 Alejo Venegas, Agonía del tránsito de la muerte, en Encarnación García Dini, Antología en defensa de la lengua y la literatura españolas (siglos XVI y XVII), Madrid, Cátedra, 2007, pp. 191-194 (p. 193).

14 Vid. Elisabetta Sarmatti, Le critiche ai libri di cavalleria nel Cinquecento spagnolo (con uno sguardo sul seicento). Un' analisi testuale, Pisa, Giardini Editori, 1996. 
Malón de Chaide en su Conversión de la Magdalena, de 1585, recordemos la de Luis de León en su Apología de las obras de Santa Teresa de Jesús, de 1589 ("condenarán los libros de Celestina, los de Caballerías, y otras mil prosas y obras llenas de vanidades y lascivias, con que en cada momento se empozońan el alma") ${ }^{15}$, la de Francisco Ortiz Lucio en su Jardin de amores santos, de 1589 ("es muy inútil y de poco provecho la lección de las Celestinas, Dianas, Boscanes, Amadises, Esplandianes y otros libros llenos de portentosas mentiras") ${ }^{16}$ o, por no abundar más, la de fray Pedro de la Vega, quien en su Declaración de los sietes psalmos penitenciales, de 1602, habla de "desterrar de las manos de la donzella, de la viuda, y a veces de la monja, y de muchos otros las Dianas, Amadises, y demás libros profanos (de los quales los menos dañosos están llenos de vanidad y mentiras)"17. Incluso en el Nuevo Mundo hubo normas contra la importación de la ficción, normas que demuestran su percepción como grupo; así, en la constitución vigesimotercera del sinodo de Santiago de Tucumán (1597) se ordena que "no traigan ni envíen a las casas de nuestra morada todos los libros que se intitulan Dianas, de cualquier autor que sean, y el libro que se intitula La Celestina, y los libros de caballerías y las poesías torpes y deshonestas", a los que se califica como "vanas y mentirosas fábulas"18.

Recordemos que, en la anterior cita cervantina, don Quijote habla de "las Amarilis, las Filis, las Silvias, las Dianas, las Galateas, las Fílidas y otras tales de que los libros, los romances, las tiendas de los barberos, los teatros de las comedias, están llenos" ${ }^{19}$. La nómina de nombres parece extraída más bien de la poesía bucólica o de libros de pastores, y alude expresamente a libros, romances y teatros. Se trata, por tanto, de una visión de conjunto de la ficción, que abarca tanto a la prosa como al verso, sin olvidar la representación teatral.

Todo esto nos da pistas sobre la forma como se recibían estas obras, así como del proceso de escritura y de creación literaria en esos años. En primer lugar, en la época se concebían vínculos entre obras y gru-

15 Apud Elisabetta Sarmati, op. cit., p. 160.

16 Ibidem, p. 161.

17 Ibidem, p. 273.

18 Ibidem, p. 165.

19 Miguel de Cervantes, El ingenioso hidalgo don Quijote de la Mancha, p. 251. 
pos de ficción hoy día considerados normalmente de forma aislada. Lope de Vega ofrece un claro testimonio de cómo la narración de ficción se contemplaba como un conjunto de vasos comunicantes, cuando en sus Novelas a Marcia Leonarda identifica cuento y novela, al tiempo que los entronca con los libros de caballerías:

y se llamaban en lenguaje puro castellano caballerias, como si dijésemos "hechos de grandes caballeros valerosos". Fueron en esto los españoles ingeniosísimos, porque en la invención ninguna nación del mundo les ha hecho ventaja, como se ve en tantos Esplandianes, Febos, Palmerines, Lisuartes, Florambelos, Esferamundos y el celebrado Amadis, padre de toda esta máquina que compuso una dama portuguesa $^{20}$.

Lope continúa vinculando este género con el de la épica culta: "El Boyardo, el Ariosto y otros siguieron este género, si bien en verso" ${ }^{21}$. Como es sabido, continúa indicando que también en España hay libros de novelas (se refiere, claro está, a la novela corta). Esto es, ofrece un repaso a ciertas formas literarias que considera emparentadas de algún modo. Aquello que las une, el rasgo común que comparten, es su carácter de ficción narrativa. Lope no duda en considerar la épica culta italiana como libros de caballerías en verso. La ficción en el Siglo de Oro parece llevar siempre a los libros de caballerías como objetivo de sus críticas, lo que a su vez demuestra que eran el prototipo de ficción ${ }^{22}$.

Encontramos otro testimonio en Tirso de Molina, quien, en la dedicatoria a Deleitar aprovechando, menciona de forma conjunta a "los autores de los Belianises, Febos, Primaleones, Dianas, Guzmanes de Alfarache, Gerardos y Persiles" de los que dice "que todos son patrañas") ${ }^{23}$. De nuevo,

20 Lope de Vega, Las fortunas de Diana, en Novelas a Marcia Leonarda, ed. Antonio Carreńo, Madrid, Cátedra, 2002, pp. 104-105.

21 Ibidem.

22 Sobre este tema, vid. José Julio Martín Romero, "En torno a la relación entre la épica áurea y los libros de caballerías", en "Et era muy acuçioso en allegar el saber". Studia Philologica in honorem Juan Paredes, eds. Eva Muñoz Raya y Enrique J. Nogueras Valdivieso, Granada, Universidad de Granada, 2019, pp. 509-524.

23 Tirso de Molina, Deleitar aprovechando, ed. Pilar Palomo, Madrid, Turner-Biblioteca Castro, 1994, p. 9. 
se trata de un elenco de obras pertenecientes a géneros que actualmente se consideran diferentes, pero que en la recepción de la época se contemplaban como unidas por su carácter de literatura de ficción. Todo ello demuestra que en la época la ficción se contemplaba de una manera mucho menos fragmentada y que la poética de los géneros resultaba mucho más abierta de lo que hoy día se piensa.

Por otra parte, quizá la clasificación tradicional deba ser reevaluada. El abrumador volumen de la producción narrativa áurea ha forzado a una categorización que facilitara su estudio ${ }^{24}$. A pesar de las bondades de la misma, lo cierto es que no faltan determinados puntos débiles: fundamentalmente la equiparación de diversos grupos que no pueden ser considerados al mismo nivel. Es evidente que el empleo del término género implica nociones diferentes si se aplica a una determinada variedad narrativa o a otra. En primer lugar, se habla de grupos literarios cuyas características formales y temáticas permitían a la recepción contemporánea considerarlos como tal grupo, es el caso de los libros de caballerías. Si bien la forma de entender este sintagma no coincide necesariamente con el uso del marbete utilizado hoy por la crítica, no se puede negar que existía una clara conciencia de lo que era un libro de caballerías, y así lo confirma el testimonio (ya en el Seiscientos) del lexicógrafo Covarrubias en su Tesoro de la lengua castellana o española.

Por su parte, otro grupo, el de los libros de pastores, también era claramente reconocido como tal en la recepción contemporánea. El sintagma se usó en el Siglo de Oro; recordemos que así lo hizo Lope de Vega en Las fortunas de Diana:

Dioles las gracias Diana, y preguntándole ellos la causa de su mal, les dijo que había caminado sin comer tres días. Entonces sacó Filis de su zurrón lo que vuestra merced habrá oído que suelen traer en los libros de pastores; y

24 El valor pedagógico de clasificaciones como la propuesta por Antonio Rey Hazas ("Introducción a la novela del Siglo de Oro, I. (Formas de narrativa idealista)", Edad de Oro, 1 (1982), pp. 65-105) resulta evidente, y se ha seguido en numerosos estudios, como, por citar solo un ejemplo, la monografía de María Soledad Carrasco Urgoiti, Francisco López Estrada y Félix Carrasco, La novela española del siglo XVI, Madrid-Frankfurt am Main, Iberoamericana-Vervuert, 2001. 
esforzándose Diana a comer, a su ruego, fortificó la flaqueza con templanza, y sintió el desmayado cuerpo algún alivio $^{25}$.

Otra variedad narrativa, la de la novela o ficción sentimental, hubo de ser percibida como tal género también entre sus contemporáneos, si bien el sintagma empleado hoy por la crítica no fue nunca el que se usó en aquellos años ${ }^{26}$.

En estos tres casos, los grupos se vinculaban con sendos paradigmas; este podía ser la primera obra de dicha modalidad. Así, la reescritura por Garci Rodríguez de Montalvo de Amadís de Gaula (1508) fue el paradigma para los libros de caballerías; y La Diana (c. 1558-1559), de Jorge de Montemayor, lo fue para los libros de pastores. Pero no sucede igual en el género sentimental, ya que fue la Cárcel de Amor de Diego de San Pedro, impresa por vez primera en 1492, la obra contemplada en el Quinientos como la novela sentimental prototípica, a causa de su éxito editorial a lo largo del siglo XVI (no obstante, la situación del género sentimental a lo largo del siglo XV había sido distinta ${ }^{27}$. Por otra parte, este último género pronto se dejó influir también por La Celestina (1499) y la tradición celestinesca, como demuestra la Penitencia de amor (impresa en 1514), de Pedro Manuel Jiménez de Urrea. Todo ello revela una situación mucho más compleja de relaciones con el paradigma de lo que se tiende a pensar.

Un caso peculiar es el de la literatura picaresca, que presenta un desarrollo distinto: su paradigma, el Lazarillo (1554), no se contempló como tal hasta que apareció décadas después el Guzmán de Alfarache de Mateo

25 Lope de Vega, op. cit., p. 138.

26 Es fundamental el estudio sobre este género de Tobias Brandenberger, La muerte de la ficción sentimental. Transformaciones de un género iberorrománico, Madrid, Editorial Verbum, 2012. El investigador amplía considerablemente el panorama, tanto en corpus como en cronología.

27 La ficción sentimental tenía ya un largo recorrido desde el Siervo libre de amor (mediados del siglo XV) de Juan Rodríguez del Padrón; lógicamente, los numerosos textos de este género hasta 1492, fecha de la primera edición de la Cárcel de amor, no tomaron esta obra como paradigma. Sin embargo, el género estuvo ligado a la influencia del texto de Diego de San Pedro a partir de la impresión en 1492. 
Alemán. Esta publicación de 1599 determina que en realidad el género se desarrollará realmente a lo largo del siglo XVII ${ }^{28}$.

Más problemática resulta la consideración de otras variedades narrativas como géneros. Es el caso de los textos quinientistas de la llamada novela bizantina (la situación es distinta en la centuria siguiente). En el siglo XVI contó únicamente con dos títulos (si no tomamos en cuenta las traducciones de Heliodoro); uno de ellos, el Clareo y Florisea, de Núñez de Reinoso, es bizantino en tanto que parte de él -y solo parte- reescribe los Raggionamenti d'amore de Ludovico Dolce (a su vez reescritura de la obra de Aquiles Tacio, Leucipe y Clitofonte). En virtud de ese modelo griego, tamizado por el texto italiano, la obra de Reinoso puede considerarse la primera obra bizantina, pero es un libro mucho más complejo, con una segunda parte alegórica que se desvía de esas fuentes. Además, la figura de Isea parece orientarlo más hacia el ámbito de lo sentimental:

Si mis grandes tristezas, trabajos y desventuras por otra Ysea fueren oýdas, yo soi çierta que serán no menos lloradas que con razón sentidas; pero, con todo, pienso que pues mis tristes lágrimas ablandaron y enterneçieron las duras piedras, que ansí harán a los blandos y tiernos coraçones, so pena que no siendo ansí, confesarán que son más duros que las duras peñas. Esta mi obra, que solamente para mí escrivo, es toda triste, como yo lo soi; es toda de llantos y de grandes tristezas, porque ansí conforme con todas mis cosas y tenga el hábito que yo tengo ${ }^{29}$.

El otro título, la Selva de Aventuras, de Jerónimo de Contreras, parece más bien un libro de peregrinación que, como ha estudiado Miguel Ángel

28 Coincido con Pedro Ruiz, "Prácticas y oficios de narrar en el siglo XVI: historia y teoría", Studia Aurea, 9 (2015), pp. 9-48, que afirma que "entre las obras que acaban encontrando con mayor o menor acomodo un género propio cabría situar un texto tan señero como el Lazarillo, inclasificable como 'novela picaresca' antes de 1599, cuando Mateo Alemán retoma algunos de sus rasgos para su Guzmán de Alfarache" (p. 13). No es el momento aquí de recoger toda la bibliografía sobre este tema, pues la complejidad del género ha hecho correr ríos de tinta. Es precisamente dicha complejidad - a la hora de definir sus rasgos y su definición- la que sirve a mis argumentos.

29 Alonso Núnez de Reinoso, Historia de los amores de Clareo y Florisea y de los trabajos de Isea, ed. José Jiménez Ruiz, Málaga, Universidad de Málaga, 1997, p. 97. 
Teijeiro, únicamente en la edición posterior de 1582 se acomodó a ese modelo de amantes separados que finalmente se reúnen, lo que implicó la incorporación de dos libros más que narraban los viajes de la dama; esta, en la primera versión, se mantenía estática y, además, ni siquiera aceptaba el amor del caballero cuando se reencontraban al final ${ }^{30}$. Por tanto, este supuesto género del siglo XVI solo registra dos títulos que, aunque pueden tener vínculos con lo bizantino, presentan características diversas entre sí y en la recepción de la época seguramente no eran vistos como pertenecientes al mismo grupo (aunque es cierto que la situación será distinta en el siglo XVII, con varias obras que asumen a Heliodoro como modelo) ${ }^{31}$.

Probablemente el marbete más controvertido sea el de novela morisca, que a mi parecer se debe considerar más un tema que un género propiamente dicho. La inclusión en este supuesto género del Abencerraje, las Guerras civiles de Granada de Ginés Pérez de Hita, Ozmin y Daraja de Mateo Alemán y la historia del cautivo en el Quijote se antoja un tanto extraña. No niego que exista algún punto común, pero se trata fundamentalmente de ciertos temas; considero que carece de una poética de género que sí encontramos en otras modalidades. En este sentido, dudo de que cumpla las condiciones necesarias para ser considerado como tal ${ }^{32}$.

Por tanto, existen géneros reconocidos en la época, otros que fueron conformándose en el siglo XVII, y otros que apenas pueden ser etiquetados como tales.

Por otra parte, el acercamiento en compartimentos estancos ha propiciado ciertas visiones inadecuadas de la evolución de la narrativa áurea (sobre todo la del siglo XVI). El análisis de las interrelaciones entre estas

30 Jerónimo Contreras, Selva de aventuras, ed. Miguel Ángel Teijeiro, Cáceres, Institución Fernando el Católico / Universidad de Extremadura, 1991; y Miguel Ángel Teijeiro, "Jerónimo Contreras y los nueve libros de la Selva de aventuras: aproximación al modelo bizantino", Anuario de Estudios Filológicos, 10 (1987), pp. 345-359.

31 Javier González Rovira, La novela bizantina de la Edad de Oro, Madrid, Gredos, 1996.

32 No es el momento aquí de exponer toda una teoría sobre los géneros literarios. Mi objetivo es demostrar que en la clasificación tradicional de los géneros narrativos áureos se siguen parámetros distintos para cada uno de ellos, de forma que no se puede admitir que sean equivalentes (en el sentido de que solo son géneros si se utilizan diversos conceptos de ese término). 
modalidades narrativas evidencia que quizá los límites no fueron nunca tan marcados como pudiera pensarse hoy día. Cada obra de un determinado género podía alimentarse no sólo de las anteriores incluidas en el mismo, sino también de toda la producción literaria previa. No se trata únicamente de un empleo de fuentes de carácter heterogéneo; consiste en una visión de la narrativa de ficción que en muchos casos rompe con las barreras que artificialmente se crean en la historiografía actual ${ }^{33}$.

Me limitaré a exponer tan solo unos cuantos ejemplos. En primer lugar, como ya indicó Kossoff, en la Selva de aventuras se encuentran elementos "que coinciden con la materia de la novela sentimental, la novela pastoril, los tratados de amor, el Cortesano y el Galateo"34. Otro caso conocido es el episodio pastoril que aparece en Clareo y Florisea de Núñez de Reinoso, que, como se ha dicho, tradicionalmente se considera una novela bizantina. Se trata de unos capítulos en los que la aventura pastoril se inserta en la historia de separación de los amantes, pero que, claro está, no deriva de ningún libro de pastores (pues no habían aparecido en esa época) ni es una reescritura prosística de un poema bucólico. Procede, como es sabido, de los Floriseles de Feliciano de Silva, amigo de Núñez de Rei-

33 Sobre los distintos conceptos de género (histórico, teórico, etc.), es fundamental el estudio de Tzvetan Todorov, Les genres du discours, Paris, Éditions du Seuil, 1978; y "El origen de los géneros", en Miguel Ángel Garrido Gallardo, Teoría de los géneros literarios, Madrid, Arco Libros, 1988, pp. 31-48. Acerca de las designaciones del propio texto (historia, crónica, etc.), véase Víctor Infantes, “Tipologías de la enunciación literaria en la prosa áurea. Seis títulos (y algunos más) en busca de un género: obra, libro, tratado, crónica, historia, cuento, etc. (IV)", en Actas del XIII Congreso de la Asociación Internacional de Hispanistas: Madrid 6-11 de julio de 1998, coords. Florencio Sevilla Arroyo y Carlos Alvar Ezquerra, Madrid, Castalia, 2000, III, pp. 641-654; y, del mismo autor, "Tipologías de la enunciación literaria de la prosa áurea: seis títulos (y algunos más) en busca de un género: obra, libro, tratado, crónica, historia, cuento, etc... (VI)", en Memoria de la palabra: actas del VI Congreso de la Asociación Internacional Siglo de Oro. Burgos-La Rioja 15-19 de julio 2002, eds. Francisco Domínguez Matito y María Luisa Lobato López, Madrid / Frankfurt am Main / Logrońo, Iberoamericana / Vervuert / Fundación San Millán de la Cogolla, 2004, II, pp. 1059-1071.

34 Ruth H. Kossof, "Las dos versiones de la Selva de aventuras de Jerónimo de Contreras", en Actas del VI Congreso Internacional de Hispanistas, eds. Alan M. Gordon y Evelyn Rugg, University of Toronto, 1980, pp. 435-437 (p. 436). 
noso y, por cierto, también de Jorge de Montemayor ${ }^{35}$. La singularidad de Clareo y Florisea va mucho más allá, porque presenta lazos evidentes con un género que normalmente se considera en decadencia por aquellos años: la ficción sentimental ${ }^{36}$. Según he indicado, la figura de Isea, triste narradora de la historia de los amantes (que de alguna manera también es la suya propia), vierte un desconsuelo propio de este tipo de obras. Por otro lado, la segunda parte de la novela presenta un carácter alegórico que recuerda al texto de Diego de San Pedro, pero al mismo tiempo se desarrolla en un universo con ecos claramente caballerescos.

Un caso más evidente de esa experimentación se documenta en Dechado y remate de grandes hazañas, de Esteban de Corbera, que Pedro Malo imprimió en Barcelona en 1576. Se trata de un libro de caballerías que presenta diversas singularidades. En primer lugar, entronca con la materia troyana, pues sus primeros capítulos reescriben la leyenda de la destrucción de Troya y el destino de sus protagonistas. Pero quizá el rasgo más extraño de la obra es su peculiar uso del hurto; apenas hay nada en ella que no proceda de textos anteriores en un caso de plagio compuesto único en esos años. Habrá que esperar a la Tercera Diana (1627) de Jerónimo de Tejeda para encontrar algo parecido, y aun así el de Corbera supera a este texto en la complejidad de su costura. Pues bien, uno de los momentos hurtados es una discusión sobre el amor protagonizada por dos pastores. La inclusión de la temática pastoril en los libros de caballerías no es algo ajeno al género, esa inclusión es anterior a la aparición de La Diana de Montemayor y, por tanto, se puede considerar uno de los rasgos propios del género (o, al menos, una de sus posibilidades) ${ }^{37}$. Ello explica, por cierto, el deseo de don Quijote de adoptar la vida pastoril, tras haber sido

35 Como indicó Sydney P. Cravens, "The Ínsula Deleitosa Tale in Alonso Núñez de Reinoso's Clareo y Florisea: A Tribute to Feliciano de Silva”, Hispanófila, 64 (1978), pp. 1-6, y recordó José Jiménez Ruiz en su edición de Alonso Núñez de Reinoso, Historia de los amores de Clareo y Florisea y de los trabajos de Isea, Málaga, Universidad de Málaga, 1997, p. 248, n. 37.

36 Aunque quizá esa idea de la decadencia del género sentimental en esos años deba ser puesta en duda a la luz de los datos de Tobias Brandeberger, op. cit., especialmente pp. 494-497.

37 Vid. José Julio Martín Romero, "La temática pastoril en los libros de caballerías de la época de Felipe II", Nueva Revista de Filología Hispánica, 57/2 (2009), pp. 563605. 
derrotado, mucho mejor que una posible hibridación genérica.

Pero volviendo al Dechado y remate, ese debate sobre el amor (que parece recordar a los que se daban entre Darinel y Mordacheo en las obras de Feliciano de Silva) no procede ni de los libros de pastores ni de los de caballerías. El modelo no es otro que la Selva de aventuras (1565) de Jerónimo de Contreras. En esta obra el protagonista será espectador de una representación teatral en verso en la que dos actores interpretan el papel de pastores que debaten sobre el amor. Pues bien, ese episodio es el que Corbera prosificó en su texto. Por tanto, nos encontramos con un libro de caballerías, que reescribe la materia troyana y que incluye un episodio pastoril que procede de una representación teatral narrada en el interior de una obra considerada novela bizantina. Se puede alegar que se trata únicamente del uso de fuentes heterogéneas en estos textos, que eran capaces de asumir esas fuentes para adaptarlas a la poética del nuevo género $^{38}$, pero lo cierto es que revela la libertad con que los autores decidían seguir ciertos paradigmas y, por tanto, la desigual relación de una obra con un género en concreto; es así como hay que entender la permeabilidad entre obras aparentemente alejadas.

En definitiva, si bien es difícil negar la existencia de algunos géneros (los libros de caballerías, los libros de pastores) en otros casos resulta más complejo aceptarlos como tales (la literatura bizantina, al menos en el siglo XVI; la literatura morisca). Por todo ello, quizá algunos ejemplos tradicionalmente vistos como fusión o hibridismo genérico puedan ser realmente casos de confusión terminológica.

En realidad, no hay que olvidar que el proceso creativo fundamental en el Renacimiento era la imitatio, esencial para el concepto de recuperación del pasado grecolatino como modelo. Como es sabido, la controversia sobre la imitatio permea la Europa renacentista. Hay que recordar que no se ponía en duda si se debía imitar o no, sino la forma de hacerlo. En el ámbito teórico, el debate sobre la imitatio trataba sobre los modelos lingüísticos latinos a los que se debía imitar; consistía, por tanto, en la

38 Vid. José Julio Martín Romero, “Febo el Troyano [1576] de Esteban Corbera: la reescritura caballeresca de la materia troyana”, Edad de Oro, XXI (2002), pp. 443-449; e "Introducción" a mi edición de Esteban Corbera, Febo el troyano, Alcalá de Henares, Centro de Estudios Cervantinos, 2005, pp. IX-XXIII. 
elección de autores clásicos a quienes seguir ${ }^{39}$. Ese carácter, fundamentalmente lingüístico, derivó pronto en una imitatio más amplia que implicaba aspectos literarios. Una vez la lengua vulgar se asumió como vehículo de creación, se continuó de forma natural con modelos en lenguas romances. Pero más allá de las diatribas teóricas, de los preceptos y de las controversias, la imitatio era el proceso creativo fundamental. Apenas es necesario defender esta idea. Son conocidas las palabras de Francisco Sánchez de las Brozas en sus comentarios a la obra de Garcilaso:

Digo y afirmo que no tengo por buen poeta al que no imita a los excelentes antiguos. [...] Y si me preguntan por qué entre tantos millares de poetas como nuestra España tiene, tan pocos se pueden contar dignos deste nombre, digo que no hay otra razón sino porque les faltan las ciencias, lenguas y doctrina para saber imitar ${ }^{40}$.

39 El tema ha sido bien analizado por Ángel García Galiano, La imitación poética en el Renacimiento, Kassel, Publicaciones de la Universidad de Deusto / Edition Reichenberger, 1992. La práctica imitativa, con acercamientos a la teoría sobre la imitatio, ha sido frecuentemente estudiada en el ámbito de la lírica; véanse, por ejemplo, las reflexiones de Fernando Lázaro Carreter, "Imitación compuesta y diseño retórico en la oda a Juan de Grial”, Anuario de estudios filológicos, 2 (1979), pp. 89-119; y la monografía de Jesús Ponce Cárdenas, La imitación áurea (Cervantes, Quevedo, Góngora), París, Éditions Hispaniques, 2016; en el campo de la prosa narrativa, destacamos M. a Luzdivina Cuesta Torre, "La teoría renacentista de la imitación y los libros de caballerías", en Actas del Congreso Internacional sobre Humanismo y Renacimiento, eds. Juan Matas Caballero, José Manuel Trabado Cabado, M. ${ }^{a}$ Luisa González Álvaro y Mayuela Paramio Vidal, León, Universidad de León / Servicio de Publicaciones, 1998, II, pp. 297-304; y "La estética del 'plagio' en El Quijote", Estudios Humanisticos. Filología, 19 (1997), pp. 107-123; asimismo, son interesantes los estudios de Emilio José Sales Dasí, "La imitación en las continuaciones ortodoxas del Amadís de Gaula I. Los episodios amorosos", en De la literatura caballeresca al Quijote, coord. Juan Manuel Cacho Blecua, Zaragoza, Universidad de Zaragoza, 2007, pp. 395-417; "La imitación en las continuaciones ortodoxas del Amadis II. Las aventuras bélicas y maravillosas", Tirant: Butlletí informatiu i bibliogràfic, 9 (2006), s. p.; y "Nuevos aspectos de la imitación en el Silves de la Selva, de Pedro de Luján”, Nueva Revista de Filología Hispánica, 55/2 (2007), pp. 375-395.

40 Apud Antonio Gallego Morell, Garcilaso de la Vega y sus comentaristas, Madrid, Gredos, 1972, p. 23. 
Recordemos que ya Juan de Valdés en su Diálogo de la lengua (1535) comentaba el proceso imitativo como algo connatural: "siempre acontece que assí como naturalmente tales son nuestras costumbres quales son las de aquellos con quien conversamos y platicamos, de la mesma manera es tal nuestro estilo quales son los libros que leemos" ${ }^{\text {"11. }}$. Y por ello recomienda escoger bien las obras. Cuando se le pregunta a Valdés "qué libros castellanos os parece que podamos leer para hazer buen estilo" 42 , afirma en relación a la prosa de ficción: "Entre los que an escrito cosas de sus cabeças comúnmente se tiene por mejor estilo el del que scrivió los quatro libros de Amadis de Gaula, y pienso que tienen razón"³. A sus elogios a Amadis une otros a Palmerín y Primaleón, si bien pone ciertos reparos estilísticos, fundamentados en el carácter arcaico de determinados vocablos y expresiones (sus reparos alcanzan, por cierto, incluso a La Celestina); pero, con todo, afirma: "Aunque he dicho esto de Amadís, también digo que tiene muchas y muy buenas cosas, y que es muy dino de ser leído de los que quieren aprender bien la lengua" ${ }^{44}$. Claro está, propone estas obras como modelo solo para un determinado tipo de imitatio, el de la elocutio; en los demás ámbitos critica abiertamente que se aleje de la verosimilitud: "Los que escriven mentiras las deven escrivir de suerte que lleguen, quanto fuere possible, a la verdad, de manera que puedan vender sus mentiras por verdades" ${ }^{\prime \prime}$. Sus críticas van dirigidas hacia la falta de verosimilitud $y$, si leemos en detalle, contra la falta de moral, tal como he comentado anteriormente. Coinciden así con los reproches de Alejo Venegas mencionados más arriba. En cualquier caso, lo que quiero resaltar ahora del testimonio de Valdés es su reflexión en torno al carácter imitativo de la creación literaria. Este autor es consciente de que la imitatio no es únicamente un objeto de controversias abstractas, no se queda únicamente en los tratados de retórica y de poética; en definitiva, no es solo teoría, es el proceso creativo ineludible que se evidencia en la práctica de la escritura literaria (y no solo literaria) de la Edad de Oro.

41 Juan de Valdés, Diálogo de la lengua, ed. José F. Montesinos, Madrid, Espasa-Calpe, 1976, p. 162.

42 Ibidem.

43 Ibidem, p. 173.

44 Ibidem, p. 179.

45 Ibidem, p. 177. 
Esa consideración positiva de la imitatio a veces se mezcla con la negativa del hurto (conceptos que se confunden y entremezclan); recordemos las palabras cervantinas en la Adjunta al Parnaso (1614): "se advierte que no ha de ser tenido por ladrón el poeta que hurtare algún verso ajeno y le encajare entre los suyos, como no sea todo el concepto y toda la copla entera, que en tal caso tan ladrón es como Caco" ${ }^{46}$. De ahí que Francisco Sánchez de las Brozas tuviera que defender la imitatio, pues no era sino la defensa de su práctica como comentarista de Garcilaso, cuyas fuentes había detectado (indica que es la forma de acercarse a clásicos como Ariosto, por ejemplo). Por su parte, el traductor de Orlando furioso, Hernando de Alcocer, repasa en su interesante prólogo las fuentes grecolatinas del poema ariostesco. Es más, casi parece proponer una especie de translatio imperii literaria:

Digo assí que la intención de Homero en una de sus obras fue dar los mayores loores que pudo a Achiles y en la otra a Ulixes, y Virgilio, a imitación suya, ensalzar a Eneas. Y el conde Mateo María Bayardo [sic] y Ludovico Ariosto, imitándolos ensalçar a Rugier, imitando más al latino que al griego ${ }^{47}$.

Alcocer ofrece un elenco de momentos, personajes y situaciones en las obras italianas que derivan de las clásicas; concluye que Boiardo y Ariosto no merecen menos elogios por haber seguido esos modelos: "por aver imitado de passo en passo a los passados no son menos de alabar los dos antedichos, porque según el lugar y el tiempo y las personas han variado" ${ }^{48}$. Es más, indica otros autores que les han servido como modelos de imitatio:

Tomó de Luciano el viento recogido en los odres; de Homero, las hojas convertidas en naves; de Virgilio, las piedras convertidas en hombres y caballos, la antigua fábula de Deucalión; Garbina la vieja, de Apuleyo; la cortesía del león, del Bocacio en la novela de

46 Miguel de Cervantes, Viaje del Parnaso, en Obras completas, ed. Florencio Sevilla Arroyo, Madrid, Castalia, 1999, pp. 1185-1220 (p. 1220).

47 Hernando de Alcocer, "Al lector", Orlando furioso, trad. Hernando de Alcocer, Toledo, Juan Ferrer, 1550, fol. aiii. Utilizo el ejemplar R/11017 de la Biblioteca Nacional de España. La cursiva es mía.

Ibidem. 
madona Dianora; Zerbín, de Zerbín del Garbe en la novela del Bocacio $^{49}$.

Se trata, por tanto, de un caso de imitatio ecléctica, que, a su vez, es la que encontramos de forma frecuente en las letras áureas. Recordemos los estudios de Gómez Canseco sobre Garcilaso en la Jerusalén conquistada (1609) de Lope de Vega ${ }^{50}$. Asimismo, el poeta toledano también fue objeto de una reescritura narrativa en los libros de caballerías ${ }^{51}$.

Por su parte, Jerónimo de Arbolanche, en los versos preliminares a Las Abidas (1566), habla también sobre la imitación. Sus palabras parecen implicar una defensa ante posibles críticas; esas críticas, como he dicho, apuntan en ocasiones a la práctica del hurto, que siguieron Plauto, Virgilio, Ariosto, Garcilaso y Boscán:

Ni sé hurtar las comedias y razones de Epicarmo y su pluma tan cortada, como Plauto, aquel cómico y farsero que sirvió al miserable molinero. [...] Ni usurpo versos del antiguo Homero que assí honrava sus dioses inocentes. [...] Y fue el escritor tan verdadero que a Penélope casta hizo entre dientes, sabiendo bien nosotros que no ay una que en castidad parezca al alma Luna. Ni sé tampoco hurtar de la manera que hurtó Vergilio cuanto aqueste hizo. [...]

Ni sé de quién hurtó su estilo tierno Petrarca, el que cantó la casta amante; ni sé si casta a Laura yo le diga, pues uvo fama de que fue su amiga.

49 Ibidem.

50 Luis M.a Gómez Canseco, “De la égloga a la 'epopeya trágica': Garcilaso en la Jerusalén conquistada de Lope de Vega”, Nueva Revista de Filología Hispánica, 63/1 (2015), pp. 61-79.

51 José Julio Martín Romero, "Garcilaso como objeto de imitación poética y de reescritura narrativa", en Memoria de la palabra, eds. María Luisa Lobato y Francisco Domínguez Matito, Madrid/Frankfurt, Iberoamericana/Vervuert, 2004, II, pp. 1267-1275. 
Ni sé yo como Ariosto mudar nombres

a los cuentos que Ovidio avía contado; [...]

ni como Garcilaso de la prosa

de Sannazaro coplas hago prestas.

Ni sé yo hazer mi pluma muy famosa

llevando el hurto italiano a cuestas:

como el Boscán, que tanto se me entona

porque llevó el amor en Barcelona ${ }^{52}$.

Las alusiones a los grandes autores que imitaron son empleadas por Arbolanche como escudo contra los ataques que él mismo pudiera recibir por seguir esta misma práctica.

Por tanto, en el Siglo de Oro el proceso creativo parte de un deseo de emulación de los modelos clásicos. Si el proceso imitativo es el fundamental de la creación literaria áurea, comprenderemos la relación entre los diversos títulos de un determinado género narrativo y su paradigma, que se toma como modelo al que emular. Se trata de una práctica de imitatio ecléctica que actúa con libertad en el uso de fuentes (tanto en el plano de la elocutio como en el de la materia narrativa $)^{53}$.

En tanto que la imitatio compuesta es la más frecuente, se entenderá por qué no dudaron estos autores en retomar con total libertad elementos de géneros en principio diversos ${ }^{54}$. Como he dicho, Valdés propone Amadis como digno de imitatio para "los que an escrito cosas de sus cabeças" 55 ; se trata de un interesante testimonio de cómo la literatura caballeresca fue asumida como modelo y no únicamente dentro de su género, sino para toda la ficción. Efectivamente, los libros de caballerías nutrieron al resto de modalidades; por poner tan solo un ejemplo, el análisis del reflejo en determinados libros de caballerías de los estratos más bajos de la socie-

52 Jerónimo de Arbolanche, Las Abidas, ed. facsimilar, estudio, vocabulario y notas de Francisco González Ollé, Madrid, CSIC, 1972, II, pp. 355-361.

53 De estos temas —en el ámbito narrativo- me ocupé en mi libro Entre el Renacimiento y el Barroco. Pedro de la Sierra y su obra, Zaragoza, Prensas Universitarias de Zaragoza, 2007, pp. 135-138. También son muy interesantes las reflexiones de Jesús Ponce, $o p$. cit.

54 El término fue utilizado por Lázaro Carreter, op. cit., pp. 94-97, siguiendo a Henri Weber, La création poétique au XVI siècle en France, Paris, Nizet, 1955, p. 122.

55 Juan de Valdés, Diálogo de la lengua, p. 173. 
dad, de la capacidad de algunos de sus personajes para engańar, hurtar y sacrificar la dignidad para sobrevivir en situaciones arduas nos daría más de una sorpresa e iluminaría el género picaresco.

Además, se ha de tener en cuenta que la teorización sobre la narrativa áurea no imponía modelos teóricos claros. Aquella fue una época de clara experimentación; en muchos textos, los autores no pretendían necesariamente ligarse a un paradigma único. Incluso cuando lo codiciaron, no consideraban ajeno a un género lo que participaba de otro.

A lo largo del siglo XVI se transita el camino en defensa de la ficción narrativa, un camino lleno de obstáculos, fundamentalmente moralistas, que veían esos libros como mentirosos, vacíos e inútiles, cuando no incitadores al vicio y al pecado. La defensa de la verosimilitud no era sino otra forma de moralismo, que temía en las extravagancias que, a pesar de todo, poblaban sus páginas una libertad peligrosa, una actividad amenazadora. Pero esas críticas no lograron encadenar la imaginación de los escritores áureos, la ficción se abrió paso, pues la tendencia humana a concebir realidades distintas a las que le ha tocado vivir no admite fronteras. En aquellos años de ebullición creadora, los autores no quisieron encorsetar sus obras en los límites de una imitación servil a un determinado paradigma; en muchos casos intentaron ofrecer textos que, por mucho que en ocasiones utilizaran como fuentes obras de ciertos géneros, no estaban orientados a ser percibidos como un título más de ese grupo. Lo frecuente era el deseo de renovación y actualización frente a los textos previos, incluyendo obras paradigmáticas, y esa renovación implicaba la asimilación de motivos, temas, tópicos y fórmulas propias de cualquier modalidad narrativa.

El deseo de verosimilitud no es sino un rechazo a la ficción en sí misma, a ese deseo humano de experimentar situaciones y vivencias distintas a las cotidianas. La libertad creadora de estos autores, que jugaban con modelos diversos, con paradigmas distintos, nos hace pensar que cada obra tiene una relación distinta con el género al que se tiende a adscribir, y que en varios casos no se pretendía ese tipo de adscripción que la historiografía actual propone. 